\title{
Study on the Inheritance of Wushu Teaching and Traditional Culture in Colleges and Universities
}

\author{
Li Jisong \\ Mianyang Normal University, Sichuan Mianyang, China, 621000
}

Keywords: university; martial arts teaching; traditional culture; inheritance

\begin{abstract}
With the development of the times, people pay more attention to Chinese martial arts, and some people think that they do not have the technical content. However, Chinese martial arts belong to our traditional culture and are loved by international friends. In recent years, martial arts teaching has been integrated into colleges and universities in China, but its teaching focus is on promoting the development of colleges and universities. In order to change this situation, colleges and universities should not only teach students martial arts skills, but also promote Chinese martial arts culture. This paper expounds the meaning of Chinese martial arts, studies the relationship between Chinese martial arts and traditional culture, and analyzes the inheritance of martial arts teaching and traditional culture in colleges and universities.
\end{abstract}

\section{Introduction}

Martial arts culture is an important part of Chinese traditional culture, which can reflect the value orientation and behavior methods of Chinese traditional culture. The integration of martial arts into teaching in colleges and universities is of great significance to the promotion and dissemination of Chinese martial arts culture. The martial arts culture has many functions such as entertainment, competition and fitness. It is an entertainment performance as early as the slave society. With the continuous development of human society, it gradually forms a traditional culture with Chinese characteristics. Many martial arts movements in China are suitable for all ages, and they are of great significance to improving the physical fitness of the people. Martial arts teaching in colleges and universities can enhance the national pride of Chinese students and enhance students' sense of identity with Chinese traditional culture.

\section{Chinese martial arts}

\subsection{Meaning}

Chinese martial arts not only contains rich martial arts movements, but also contains traditional culture. Its basic meanings are: using freehand or using tools to attack and defend, through martial arts routines, confrontation, etc., to achieve the purpose of physical fitness and self-defense. Chinese martial arts include traditional cultures such as religious beliefs, art of war, and philosophy. 


\subsection{Development path}

As early as the Shang and Zhou Dynasties, China has formed the dance mode of Wuwu. Through this dance, the national soldiers are trained to achieve the purpose of strengthening the body and boosting morale. During the Spring and Autumn Period and the Warring States Period, the vassal states used fighting techniques in the battlefield (Qi Gonggong held a "corner test" every year). With the continuous development of human society, sword-making skills and kendo have been greatly developed. Through the allusions of the "Xiang Wang Wu Jian, Yi Pei Gong" in the Qin and Han Dynasties, it can be found that Chinese martial arts have formed a certain routine. In the Han Dynasty, not only did the types of weapons continue to increase, but Hua Tuo also compiled the "Five Birds Play". The Tang Dynasty began to implement the martial arts system and select talents for the military. This is of great significance for promoting the development of martial arts in China. Although the Song Dynasty prohibited the people from possessing weapons, many people still chose martial arts because of the influence of Yue Fei. In the Ming Dynasty, Qi Jiguang organized the martial arts such as Changquan, Shorts, Red Boxing and Bazi Boxing in China. After the Qing Dynasty, a variety of martial arts such as Taijiquan and Neijiaquan were formed. It can be seen that China has always attached great importance to the development of martial arts.

\section{The connection between Chinese martial arts and traditional culture}

The study found that the development of Chinese martial arts is closely related to Chinese traditional culture. Chinese martial arts belongs to China's oldest type of sports operation, and its connection with traditional Chinese culture is relatively close. From the history of Chinese martial arts development, Chinese martial arts culture is worthy of our promotion. With the continuous development of China, Chinese martial arts culture has become an important part of Chinese traditional culture. If people want to learn martial arts, they need to have the will to "practice in summer and winter ". Through their constant practice and mastery of martial arts skills, they can effectively improve the psychological quality and martial arts skills of learners while continuously overcoming difficulties and exercises. Level. Chinese traditional culture attaches great importance to the cultivation of individual cultivation, and martial arts is consistent with our traditional culture on this point. Therefore, when teaching students martial arts, colleges and universities need to integrate traditional culture with martial arts and attach importance to cultivating students' selfcultivation. In this way, students can master the skills of martial arts, and at the same time improve their overall quality, and then achieve the purpose of quality education.

\section{The Significance of Wushu Teaching and Traditional Cultural Inheritance in Colleges and Universities}

The integration of martial arts teaching in physical education in colleges and universities not only enhances the physical quality of students, but also inherits traditional Chinese culture and enhances the personal qualities of students. Through martial arts teaching, students can master martial arts skills, help students to build self-confidence and enhance their courage to fight against evil forces; through martial arts teaching, students can cultivate their tough will, which has an important impact on students' future development.

\subsection{Enhance the patriotism of students in ancient China}

"Fa Jin Xing Qi" said: "It is my heart to recommend goodness and good fortune." It can be seen that China attaches great importance to martial arts, especially in feudal society, a major purpose of 
martial arts. It is to defend the country. Through the analysis of our country's history, we can find that the ancient Chinese martial arts people adhere to the concept of "national rise and fall, everyone is responsible". With the continuous development of our society, this concept has become increasingly firm in the hearts of our people. With the continuous development of science and technology and economy, the main purpose of people learning martial arts is to strengthen their physical fitness. When learning martial arts, they can exercise the minds of martial artists and cultivate their patriotism. For example, the "Jing Yu Qin Qin" is an allusion. Jing Ke martial arts is strong and patriotic, and ultimately he has dedicated his life to his country. Incorporating martial arts teaching into college physical education can promote the traditional martial arts culture of Chinese students while improving their physical fitness. By studying martial arts, students can help them correctly establish the awareness of socialist successors and enhance their patriotism. At the same time, through the teaching of martial arts, the will of the students can be exercised, so that they can continue to grow in the face of adversity, which is of great significance to the future development of the students.

\subsection{Culltivate students' enterprising spirit}

In the traditional culture of our country, we attach more importance to cultivating students' personal qualities, cultivate students' spirit of perseverance and fear of difficulties, and constantly strive to move forward after identifying the goals. When practicing martial arts skills, students can develop their enterprising spirit during the continuous exercise. When conducting martial arts teaching in colleges and universities, it is necessary to pay attention to cultivating students' awareness of persisting in learning and exercising.

\section{Problems in Cultural Heritage in the Process of Wushu Teaching}

\subsection{Wushu teaching and cultural heritage are not unified}

With the continuous development of education, colleges and universities attach more importance to quality education for students, and martial arts teaching is of great significance to the inheritance of Chinese traditional culture. In the process of martial arts teaching, some colleges and universities pay more attention to the teaching of martial arts skills, and do not pay attention to the inheritance of traditional culture, so that martial arts teaching cannot fully play its positive role.

\subsection{Missing teaching content}

At this stage, Chinese martial arts can be divided into two major categories: competitive martial arts and traditional martial arts. Competitive martial arts belongs to sports competition, and its inheritance is Chinese traditional culture. In China's martial arts teaching, most of them are competitive martial arts teaching. For example, in college martial arts textbooks, mainly for Changquan, Taijiquan, etc., it does not involve traditional martial arts and traditional culture in China, which shows that colleges and universities do not attach importance to martial arts teaching. Traditional martial arts teaching and traditional cultural heritage. As an important teaching system, if it does not pay attention to the inheritance of traditional culture, it will have a negative impact on students and social development.

\subsection{Teaching methods are not advanced enough}

The teaching of any subject requires teachers to use reasonable teaching methods for teaching. 
However, with the continuous development of science and technology, the teaching methods are gradually increasing. In some martial arts teaching in some universities, advanced teaching methods are not used, which also affects the effect of martial arts teaching. Important factors in the inheritance of martial arts culture and traditional culture. If the teacher only uses the traditional teaching mode and the fixed teaching mode to teach, it will directly affect the classroom teaching atmosphere and affect the students' interest in learning. In addition, China's martial arts culture and traditional culture are very rich. Therefore, in order to realize the inheritance of martial arts culture and traditional culture, it is necessary to build a good teaching atmosphere and stimulate students' interest in learning.

\section{Analysis of the Inheritance of Wushu Teaching and Traditional Culture in Colleges and Universities}

Chinese martial arts is an important part of Chinese traditional culture, and it has become an important part of physical education in colleges and universities in China. With the continuous development of society, Chinese martial arts has become an important part of people's improvement of physical fitness and self-defense ability. Chinese martial arts can fully display China's ideology and culture, and incorporate a large number of philosophical ideas, which are very important for the dissemination and inheritance of Chinese traditional culture. The martial arts culture in our country contains the spirit of patriotism. In the martial arts teaching, colleges and universities need to vigorously promote the spirit of patriotism and enhance students' recognition of the country and the nation. This has far-reaching influence on the development of students and society. Colleges and universities need to rely on the actual development of the school, students accept the ability, reasonably set the martial arts teaching content and class hours, so that students can cultivate the spirit of patriotism and carry forward the traditional culture of our country, which is very important to promote the stable and healthy development of our country.

\subsection{Correctly establish teaching concepts}

The audience of college martial arts teaching is students, most of them do not have professional martial arts knowledge. The main purpose of martial arts teaching in colleges and universities is to improve students' physical material, improve students' offensive and defensive skills, promote Chinese traditional culture, and cultivate students' patriotism. The study found that competitive martial arts teaching is not suitable for colleges and universities. This kind of teaching method can not effectively improve students' martial arts skills and comprehensive quality. Therefore, in order to enhance the effect of martial arts teaching, colleges and universities need to correctly establish teaching concepts.

When conducting martial arts teaching in colleges and universities, it is necessary to reasonably select the teaching content according to the actual needs of the students. If the university does not choose the appropriate teaching content according to the needs of the students, it will directly affect the students' interest in learning. At this stage, most of the college martial arts teaching is mainly boxing teaching, which does not effectively enhance students' interest in learning. Therefore, colleges and universities need to choose the appropriate martial arts textbooks. The Ministry of Education and the martial arts management department of China need to conduct in-depth research and analysis to determine what martial arts content can be integrated into martial arts teaching, what kind of martial arts students need to learn, and scientifically compile martial arts teaching materials. Due to the vast territory of China and the different customs and cultures of different ethnic groups, it is necessary to integrate local textbooks and unified textbooks when compiling teaching materials, so as to enhance the effectiveness of martial arts teaching. 


\subsection{Enrich the essence of martial arts teaching}

The study found that many colleges and universities in China have established a martial arts teaching curriculum mechanism, and hope to improve the physical quality of students and inherit the traditional culture of our country in martial arts teaching. However, there are still some problems in martial arts teaching, which will have a negative impact on the quality of martial arts teaching and cultural inheritance (for example, a single teaching method). Therefore, colleges and universities need to integrate martial arts content such as Taijiquan and Wubuquan into martial arts teaching to form a unified and perfect teaching system, which can stimulate students' enthusiasm for learning. At the same time, through the teaching of martial arts, students' physical quality can be improved, which is very important for improving the physical quality of the whole people and promoting the stable development of our society.

\subsection{Introducing martial arts talents}

In order to improve the effectiveness of martial arts teaching, colleges and universities need to introduce a large number of outstanding martial arts talent At this stage, although the comprehensive quality level of college martial arts teachers is relatively high, the inheritance of traditional culture is not emphasized in the teaching process. In order to effectively solve this problem, colleges and universities need to actively introduce excellent martial arts talents (not only need to have higher martial arts skills, but also need to understand the inheritance of martial arts culture and traditional cultural heritage). These professional teachers need to integrate martial arts culture and traditional culture into martial arts teaching. Only in this way can students' patriotism be cultivated in martial arts teaching. In addition, college martial arts teachers need to continue to learn to improve their professional skills and comprehensive quality, so as to ensure the quality of martial arts teaching. At the same time, college martial arts teachers need to study martial arts culture and traditional culture in depth, and reflect them in teaching. These are important measures to ensure the inheritance of Chinese martial arts culture and traditional culture.

\subsection{Teaching content needs to pay attention to cultivating students' traditional moral etiquette}

In recent years, the degree of economic globalization has been continuously improved, and Western thought has had a certain impact on the inheritance of Chinese traditional culture. Some young people in China are more seriously influenced by Western thoughts, and their emphasis on traditional festivals and traditional culture is decreasing. Therefore, in the process of martial arts teaching, colleges and universities need to help students to correctly understand Western thoughts and culture, cultivate students' ability to distinguish, enhance students' recognition of traditional culture, and ensure that students can correctly understand and master traditional Chinese moral etiquette knowledge. In the martial arts teaching, colleges and universities should not only explain the martial arts skills to the students, but also pay attention to the teaching of moral etiquette (this is very important to improve the quality of students). In college martial arts teaching, students need to be scientifically instructed to learn moral etiquette knowledge and cultivate students' awareness of respecting teachers. In the process of learning, students need to accurately locate their position. At the same time, they must adhere to the basic moral concept and insist on the concept of "benevolence" throughout the learning process. This will enable students to use their power to fight against evil forces after mastering martial arts skills. 


\subsection{Using a variety of media to spread martial arts culture}

At this stage, China has entered the information age and can spread a variety of cultures through the media. Therefore, in order to spread martial arts culture and promote Chinese traditional culture, it is necessary to use modern media technology reasonably. The study found that most Chinese college students understand martial arts and martial arts culture through movies, novels and TV dramas.

In the 1970s and 1980s, most of the people in China learned about martial arts and martial arts culture through movies. The representative was the movie "Shaolin Temple" produced in the 1980s. After that, the number of kung fu movies was gradually increasing, including: Crouching Tiger, Hidden Dragon, Huo Yuanjia, Su Shier, etc. These film and television works are of great significance to the dissemination of Chinese martial arts culture. The martial arts film and television works contain the national spirit and the spirit of patriotism, which are of great significance to improving the overall quality and patriotism of students. Li Xiaolong let Westerners know Chinese Kung $\mathrm{Fu}$ and began to pay attention to Chinese culture. With the increasing exchanges and cooperation between countries in the world, taekwondo and karate have gradually been introduced into China and developed. However, China's martial arts have a long history of development, and there are many types of martial arts, and martial arts contain a variety of tricks and artistic conception. Therefore, it is loved by friends from all over the world. Although the stories of Huo Yuanjia and Huang Feihong have been remake many times, each time they can arouse the audience's enthusiasm for watching.

Although these film and television works are mostly fictional plots, they can not fully reflect the history of our country, but these martial arts film and television works can stimulate the enthusiasm of the audience and cultivate the enterprising spirit of the audience. "Self-improvement, ethics and morality" are an important part of our national spirit. What is shown in "Huo Yuanjia" is its patriotic spirit and national spirit. Huo Yuanjia's Wude spirit will fully demonstrate the spirit of "thickness and morality" in traditional Chinese culture.

\section{Conclusion}

In summary, martial arts teaching is of great significance to traditional Chinese traditional culture. Therefore, Colleges and universities need to carry out martial arts teaching in a scientific way. In teaching, they not only need to cultivate students' martial arts skills, but also pay attention to the cultivation of students' personal qualities, adopt advanced teaching methods, and carry forward traditional Chinese culture from multiple angles, which hss important significance for promoting students and social development.

\section{References}

[1] Wang Junfeng. Research on the Relationship between Skills Transfer and Cultural Inheritance in College Wushu Teaching [J]. Times Education, 2016(3):200-200.

[2] Zhang Jun. Discussion on the Development and Effective Implementation of Sanda in College Wushu Teaching [J]. Martial Arts Research, 2016, 1(12): 53-55.

[3] Chen Jian, Ma Weiping. Study on the Lack of Traditional Culture and Countermeasures in College Wushu Teaching

[J]. Fujian Sport Science and Technology, 2017, 36(2): 48-50.

[4] Wang Sensen. Research on the Current Situation and Countermeasures of Wushu Teaching in Colleges and Universities [J]. Journal of Contemporary Sports Science, 2017, 7(14): 213-213.

[5] Yuan Li, Su Wen, Mo Lan. Research on the Promotion of Wu Dance to College Wushu Teaching [J]. Sports Science and Technology, 2016, 24(6): 16-18.

[6] Wang Xiaomei, Wang Yibo, Ouyang Bowen. Analysis of the Current Situation and Countermeasures of Martial Arts Teaching in Colleges and Universities [J]. Good Parents, 2017(50): 249-249. 